\title{
Trypsin-Stabilized Fluorescent Gold Nanocluster for Sensitive and Selective $\mathrm{Hg}^{2+}$ Detection
}

\author{
Hideya Kawasaki, ${ }^{\dagger}$ Kouta Yoshimura, Kenji Hamaguchi, and Ryuichi Arakawa \\ Department of Chemistry and Materials Engineering, Faculty of Chemistry, Materials and Bioengineering, \\ Kansai University, 3-3-35 Yamate, Suita, Osaka 564-8680, Japan
}

\begin{abstract}
We report on trypsin-stabilized fluorescent gold nanoclusters (Au NCs) for the sensitive and selective detection of $\mathrm{Hg}^{2+}$ ions. The Au NCs have an average size of $1 \mathrm{~nm}$ and show a red emission at $645 \mathrm{~nm}$. The photostable properties of the trypsin-stabilized Au NCs were examined, and their photochemical stability was found to be similar to that of CdSe quantum dots. The fluorescence was particularly quenched by $\mathrm{Hg}^{2+}$, and therefore the $\mathrm{Au} \mathrm{NCs}$ can be used as fluorescent sensors for sensitive and selective $\mathrm{Hg}^{2+}$ detection to a detection limit of $50 \pm 10 \mathrm{nM}$ and the quantitative detection of $\mathrm{Hg}^{2+}$ in wide and low concentration range of $50-600 \mathrm{nM}$.
\end{abstract}

(Received April 1, 2011; Accepted May 3, 2011; Published June 10, 2011)

\section{Introduction}

Ultra-small gold nanoparticles (Au NPs) from subnanometer scale to approximately $2 \mathrm{~nm}$ (also called gold nanoclusters [Au NCs]) have recently attracted much attention in the fields of physics, chemistry, material science, and biosciences because of the relative ease of their synthesis by chemical reduction of their salts in solution. This is done using stabilizing agents such as thiol and phosphine compounds. ${ }^{1-9}$ The specific characteristics of Au NCs are attributed to the ultra-small size of the NPs around $1 \mathrm{~nm}$. In contrast to Au NPs with sizes of more than $3 \mathrm{~nm}$, the Au NCs show no localized surface plasmon resonance (LSPR) band in the optical absorbance spectra. They display various interesting molecular-like properties such as discrete electronic states and size-dependent fluorescence, and have a variety of applications in the field of catalysis, chemical sensing, electronic devices, optics, and biomedics. ${ }^{10-25}$

Recently, there has been increasing interest in the development of biological synthesis for Au NPs because of the need for an environmentally acceptable solvent system and eco-friendly reducing and capping agents. ${ }^{26-28}$ Xie et al. first demonstrated the synthesis of highly fluorescent protein-stabilized Au NCs using a bovine-serum alubumin (BSA)-templated method. ${ }^{22}$ The as-prepared $\mathrm{Au}$ NCs consisted of 25 gold atoms $\left(\mathrm{Au}_{25}\right)$ with a red emission at $640 \mathrm{~nm}$. It has been suggested that the surface of $\mathrm{Au} \mathrm{NCs}$ are stabilized with $\mathrm{Au}^{+}$, which were further utilized for luminescence sensing of $\mathrm{Hg}^{2+}$ ions through fluorescence quenching by $\mathrm{Hg}^{2+}-\mathrm{Au}^{+}$interaction. ${ }^{29}$ Although it is not yet clear how the protein-stabilized Au NCs are formed in the solution synthesis, it has been suggested that rich tyrosine (Tyr) and cystein (Cys) residues (34 Cys and 21 Tyr) in BSA are important to produce the protein-stabilized Au NCs. This is because Cys residues, similar to thiol-protected Au NCs, are able to stabilize Au NCs, and Tyr residues can reduce $\mathrm{Au}(\mathrm{III})$

† To whom correspondence should be addressed.

E-mail: hkawa@kansai-u.ac.jp ions in alkaline $\mathrm{pH}$ above the $\mathrm{p} K_{\mathrm{a}}$ of $\operatorname{Tyr}(\sim 10){ }^{22}$

On the basis of these previous studies, proteins with rich Cys and Tyr sequences are considered to be strong candidates for the synthesis of protein-stabilized Au NCs. Thus, there are many natural proteins that are highly likely to produce such Au NCs, and the use of various proteins for protein-stabilized Au NCs may lead to the production of nanomaterials with highly specific or multiple functions, or protein-mediated self-assembly. However, so far only a few protein systems (i.e., BSA and lysozyme) are available for protein-stabilized fluorescent $\mathrm{Au}$ NCs. ${ }^{22,29-31}$

In the present paper, we report on the synthesis of trypsin-stabilized fluorescent $\mathrm{Au}$ NCs with a red emission by mixing trypsin and $\mathrm{HAuCl}_{4}$ at $\mathrm{pH} 12$. Trypsin is a serine protease found in the digestive system of many vertebrates, where it hydrolyses proteins. Trypsin is also a strong candidate for the synthesis of protein-stabilized Au NCs, since trypsin includes rich amino acid residues with $7 \mathrm{Cys}$ and 10 Tyr. The photostable properties of the trypsin-stabilized Au NCs and the effectiveness of fluorescent-based heavy metal ion sensing were examined. We found that the fluorescence was particularly quenched by $\mathrm{Hg}^{2+}$, and therefore, the Au NCs can be used as sensors for sensitive and selective $\mathrm{Hg}^{2+}$ detection to a detection limit of $50 \pm 10 \mathrm{nM}$. The quantitative detection of $\mathrm{Hg}^{2+}$ was possible over the wide and low concentration range of $50-600 \mathrm{nM}$.

\section{Experimental}

\section{Reagents}

$\mathrm{HAuCl}_{4} \cdot 4 \mathrm{H}_{2} \mathrm{O}(99.9 \%)$ as a source of gold atoms was obtained from Wako Chemical Co., from where we also purchased trypsin. Standard heavy metal solutions $\left(\mathrm{CaCO}_{3}(1002 \mathrm{mg} / \mathrm{l})\right.$, $\mathrm{Cd}\left(\mathrm{NO}_{3}\right)_{2} \quad(1001 \mathrm{mg} / \mathrm{l}), \quad \mathrm{Co}\left(\mathrm{NO}_{3}\right)_{2} \quad(1001 \mathrm{mg} / \mathrm{l}), \quad \mathrm{HgCl}_{2}$ $(1000 \mathrm{mg} / \mathrm{l}), \mathrm{Mg}\left(\mathrm{NO}_{3}\right)_{2} \quad(1001 \mathrm{mg} / \mathrm{l}), \mathrm{Ni}\left(\mathrm{NO}_{3}\right)_{2} \quad(1001 \mathrm{mg} / \mathrm{l})$, $\left.\mathrm{Pb}\left(\mathrm{NO}_{3}\right)_{2}(997 \mathrm{mg} / \mathrm{l}), \mathrm{Zn}\left(\mathrm{NO}_{3}\right)_{2}(1005 \mathrm{mg} / \mathrm{l})\right)$ were obtained from Wako Chemical Co. The ultra-pure water used throughout 

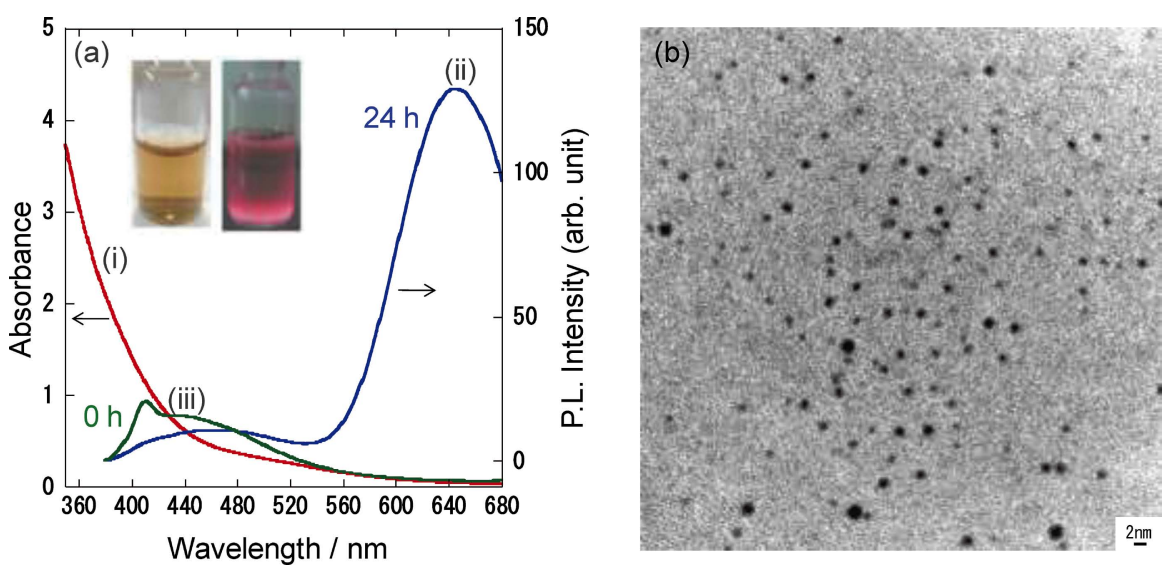

Fig. 1 (a) (i) UV-visible spectrum of aqueous solution of trypsin-stabilized Au NCs at pH 12 (a red line). Photoluminescence spectra of an aqueous solution of trypsin-stabilized Au NCs at $\lambda_{\text {ex }}=360 \mathrm{~nm}$ (ii) after $24 \mathrm{~h}$ of the reaction at $37^{\circ} \mathrm{C}$ (a blue line) and (iii) before the reaction ( $0 \mathrm{~h}$ ) (a green line). Photographs of trypsin-stabilized Au NCs in solutions under a room light (left side) and UV light of $365 \mathrm{~nm}$ (right side) are shown. (b) TEM image of trypsin-stabilized Au NCs.

all experiments was purified with an Advantec RFD $250 \mathrm{NB}$ system. All other chemicals used in this study were of reagent grade from Wako Chemical Co., and were used without further purification.

Synthesis of trypsin-stabilized Au NCs: Trypsin-stabilized $\mathrm{Au}$ NCs with a red emission were prepared according to the procedure by Xie et al. ${ }^{22}$ During a typical synthesis, the trypsin-stabilized Au NCs were prepared by mixing an aqueous trypsin solution $(0.5 \mathrm{~mL}, 20 \mathrm{mg} / \mathrm{mL})$ and an aqueous $\mathrm{HAuCl}_{4}$ solution $(0.5 \mathrm{~mL}, 5 \mathrm{mM})$ under vigorous stirring. After $1 \mathrm{~min}$, an aqueous $\mathrm{NaOH}$ solution $(0.15 \mathrm{~mL}, 1 \mathrm{M})$ was added to this solution to adjust the $\mathrm{pH}$ to 12 , and the mixture was incubated at $37^{\circ} \mathrm{C}$ for $24 \mathrm{~h}$.

\section{Apparatus}

Optical properties. UV-visible absorption spectra were measured using a JASCO V-670 spectrometer. Fluorescence excitation and emission spectra were obtained on a JASCO FP-6300 fluorometer. The photochemical stability (i.e., photobleaching) of Au clusters was examined using UV light (SLUV-6, AS ONE Co., Japan) of $1.3 \mathrm{~mW} / \mathrm{cm}^{2}$ at a distance of $5 \mathrm{~cm}$ from the light.

Circular dichroism (CD) spectroscopy. The CD spectra of aqueous solutions ( $\mathrm{pH} \mathrm{12)}$ of trypsin and trypsin-stabilized $\mathrm{Au}$ NCs were obtained using a JASCO J-820 spectropolarimeter. $X$-ray photoelectron spectroscopy (XPS). X-ray photoelectron spectra were recorded with a Quantera SXM spectrometer (Physical Electronics, Inc.) using the monochromatic $\mathrm{Al} \mathrm{K}$ line $(1486.7 \mathrm{eV})$. The base pressure was approximately $2 \times 10^{-8}$ torr. The binding energies were referenced to $\mathrm{C} 1 \mathrm{~s}$ at $284.7 \mathrm{eV}$ from hydrocarbon to compensate for the charging effect.

Transmission electron microscopy (TEM). A drop of NCs dispersed in water was placed on a carbon-coated $\mathrm{Cu}$ grid, and TEM images were recorded with a JEOL JEM-2010F at an acceleration voltage of $200 \mathrm{kV}$.

\section{Results and Discussion}

Trypsin-stabilized fluorescence Au NCs with a red emission

The UV-visible absorption spectrum of the as-prepared trypsin-stabilized Au NCs solution shows a continuous absorption increase from around $700 \mathrm{~nm}$ (Fig. 1a (i)). It is known that Au NPs with sizes of more than $3 \mathrm{~nm}$ show the LSPR absorption band $(\sim 520 \mathrm{~nm})$ in the UV-visible spectrum, while Au NCs with sizes less of than $2 \mathrm{~nm}$ exhibit no LSPR band. The fact that the LSPR band was not observed for as-prepared trypsin-stabilized Au NCs suggests that the Au NCs have core diameters of less than $2 \mathrm{~nm}$. Such tiny particle formation of the trypsin-stabilized Au NCs was confirmed by TEM observations which show their diameter to be approximately $1-2 \mathrm{~nm}$ (Fig. 1b). This indicates that $\mathrm{AuCl}_{4}^{-}$ ions are reduced to $\mathrm{Au}_{0}$ atoms and grow to form $\mathrm{Au} \mathrm{NCs}$ by using trypsin as a reducing and stabilizing agent; however, there is no further growth into large Au NPs.

After just mixing $\mathrm{HAuCl}_{4}$ and trypsin (i.e., the reaction time of $0 \mathrm{~h}$ ), the yellow solution showed no red fluorescence (Fig. 1a (iii)). After reacting for $0.5 \mathrm{~h}$, trypsin-stabilized $\mathrm{Au}$ NCs showed a red fluorescence under UV light $(365 \mathrm{~nm})$, characteristic of $\mathrm{Au}_{25} \mathrm{NCs}$. The fluorescence intensities gradually increases with the reaction times (not shown). After the reaction for $24 \mathrm{~h}$, the red emission peak of the trypsin-stabilized Au NCs was observed, as shown in the photograph in Fig. 1a. The fluorescence peak appeared at an emission of wavelength of $\lambda_{\mathrm{em}}=645 \mathrm{~nm}$ with an excitation of wavelength of $\lambda_{\mathrm{ex}}=360 \mathrm{~nm}$ (Fig. 1a (ii)), which is consistent with red emission at $\lambda_{\mathrm{em}}=640 \mathrm{~nm}$ from the BSA-stabilized $\mathrm{Au}_{25} \mathrm{NCs}_{22}$ and that at $\lambda_{\mathrm{em}}=657 \mathrm{~nm}$ from the lysozyme-stabilized $\mathrm{Au}_{25} \mathrm{NCs}^{29}$ Therefore, the trypsin-stabilized Au NCs are presumed to consist of 25 gold atoms $\left(\mathrm{Au}_{25}\right)$.

It is known that the binding energy of the metal cluster increases with a decrease in the cluster size in the XPS spectra. ${ }^{13}$ Bulk Au metal has a $\mathrm{Au}\left(4 \mathrm{f}_{7 / 2}\right)$ binding energy of $84 \mathrm{eV}$, while the $\mathrm{Au}$ binding energy of $\mathrm{Au}$ clusters could be $1.0-2.0 \mathrm{eV}$ higher. Tanaka and coworkers found from detailed peak shape analysis that the $\mathrm{Au}\left(4 \mathrm{f}_{7 / 2}\right)$ peaks can be deconvoluted into two components associated with the inner and surface atoms of gold. $^{32}$ The $\mathrm{Au}\left(4 \mathrm{f}_{7 / 2}\right)$ peak positions for the inner $\mathrm{Au}$ atoms were found to monotonically shift from 84.0 to $84.3 \mathrm{eV}$ with a reduction of the core size. The $\mathrm{Au}\left(4 \mathrm{f}_{7 / 2}\right)$ peak positions of the surface $\mathrm{Au}$ components were at higher energy $(84.3-84.7 \mathrm{eV})$ than those of the corresponding inner components. It has also been reported that the $\mathrm{Au}\left(4 \mathrm{f}_{7 / 2}\right)$ peak component from $\mathrm{Au}-\mathrm{S}$ 

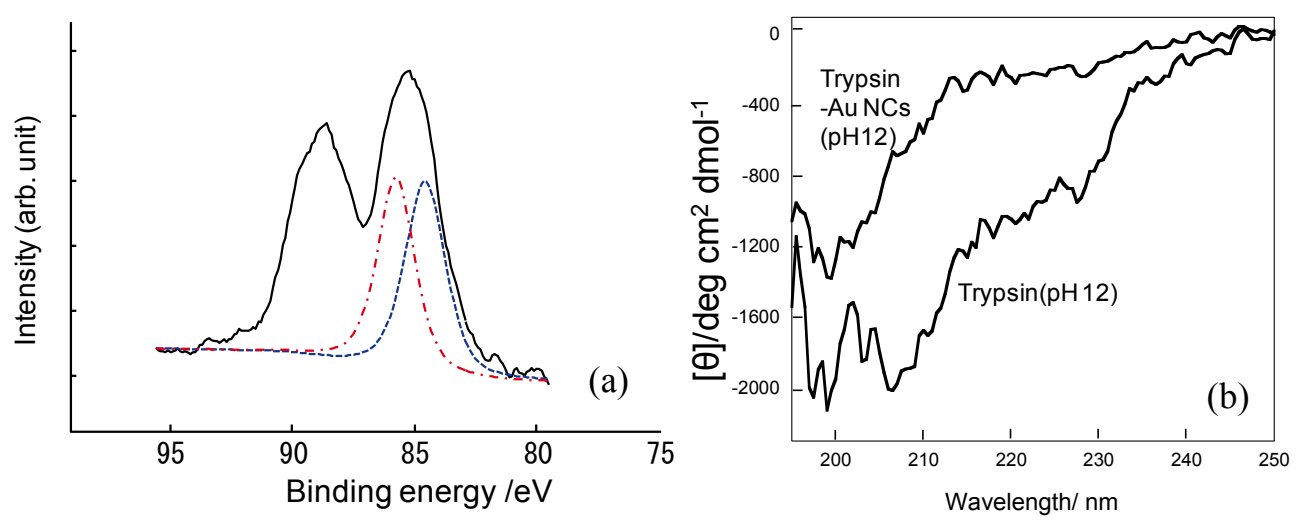

Fig. 2 (a) XPS spectra of the binding energy of $\mathrm{Au} 4 \mathrm{f}_{2 / 7}$ peak in trypsin-stabilized Au NCs. The binding energy of $\mathrm{Au} 4 \mathrm{f}_{2 / 7}$ could be deconvoluted into two distinct components at $84.0 \mathrm{eV}$ (a dot blue line) and $85.5 \mathrm{eV}$ (a dot red line). (b) $\mathrm{CD}$ spectrum of the aqueous solution of trypsin-stabilized $\mathrm{Au}$ NCs at $\mathrm{pH} 12$ and that of pure trypsin at $\mathrm{pH} 12$.
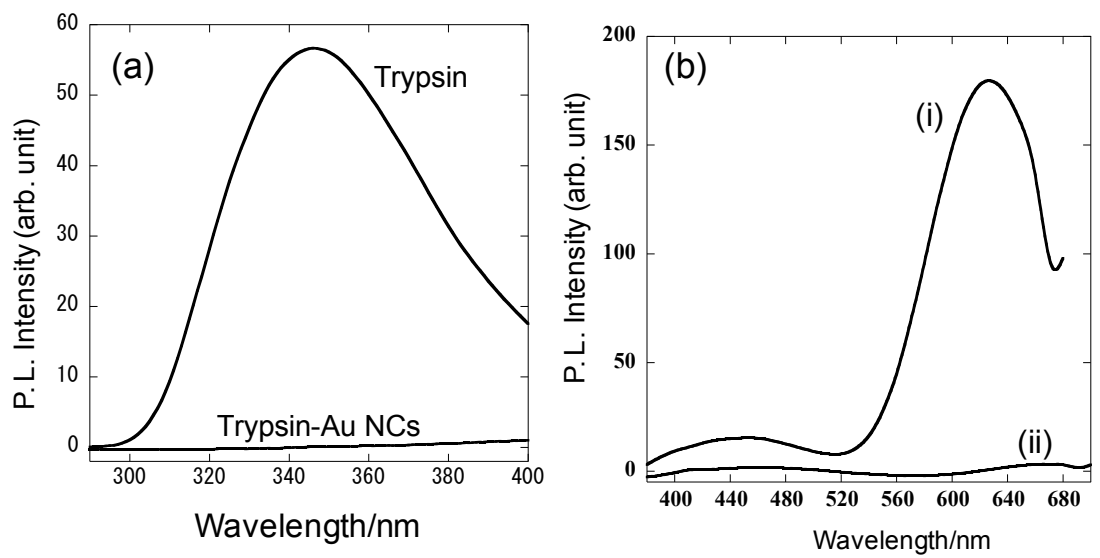

Fig. 3 (a) Photoluminescence spectra from aqueous solutions of trypsin and trypsin-stabilized Au NCs with $\lambda_{\mathrm{ex}}=280 \mathrm{~nm}$ at $\mathrm{pH} 12$. (b) Photoluminescence spectra of aqueous solution of trypsin-stabilized Au NCs at $\lambda_{\mathrm{ex}}=360 \mathrm{~nm}$ obtained from the preparation (i) in the absence and (ii) in the presence of the $8 \mathrm{M}$ urea at $\mathrm{pH} 12$.

bonds in thiolate-stabilized Au NPs is positively shifted relative to that from the $\mathrm{Au}-\mathrm{Au}$ bonds. ${ }^{33}$ In the present case, thus, the binding energy of the Au $\left(4 \mathrm{f}_{7 / 2}\right)$ peak for trypsin-stabilized $\mathrm{Au}$ NCs could be deconvoluted into two distinct components at 84.0 and $85.5 \mathrm{eV}$ (Fig. 2a). The binding energy at $84.0 \mathrm{eV}$ can be assigned to $\mathrm{Au}(0)$ atoms. Two contributions may be considered for the shifts in binding energy by $1.5 \mathrm{eV}$ toward the higher energy of trypsin-stabilized Au NCs (relative to the $\mathrm{Au}(0))$. One contribution is that the higher binding energy $(85.5 \mathrm{eV})$ of trypsin-stabilized $\mathrm{Au} 4 \mathrm{f}_{2 / 7}$ can be attributed to the surface $\mathrm{Au}$ components with higher energy. ${ }^{32}$ Another contribution is that the higher binding energy originated from $\mathrm{Au}-\mathrm{S}$ bonds in trypsin-stabilized Au NCs. ${ }^{33}$

To check whether or not any conformational changes occurred in the trypsin of $\mathrm{Au} \mathrm{NCs,} \mathrm{CD} \mathrm{spectroscopy} \mathrm{was} \mathrm{performed} \mathrm{for}$ trypsin-stabilized Au NCs and pure trypsin. The CD spectrum is useful for studying the secondary structures of proteins. Alpha-helix, beta-sheet, and random coil structures each give rise to a characteristic shape and magnitude of the $\mathrm{CD}$ spectrum. The CD spectrum shows negative bands around 208 and $227 \mathrm{~nm}$ for proteins with rich alpha-helix structures, while it shows a negative band around $215 \mathrm{~nm}$ for proteins with rich beta-sheet structures. For the random coil structure of a protein, a small positive band at $212 \mathrm{~nm}$ and a large negative one at around $195 \mathrm{~nm}$ are observed in the CD spectrum. The CD spectra of the trypsin-stabilized $\mathrm{Au} \mathrm{NCs}$ and pure trypsin at $\mathrm{pH} 12$ both showed a large negative band at around $195 \mathrm{~nm}$ from the random coil structure (Fig. 2b), indicating a large conformational change for the trypsin-stabilized Au NCs as well as pure trypsin at $\mathrm{pH} 12$. This is in contrast to the case of BSA-stabilized Au NCs, where the encapsulation of Au NCs in BSA has little effect on the structure of the BSA scaffolds. ${ }^{22}$

The addition of $\mathrm{NaOH}$ was essential to produce the trypsin-stabilized $\mathrm{Au} \mathrm{NCs,} \mathrm{and} \mathrm{when} \mathrm{NaOH}$ was not added, or under acidic conditions of $\mathrm{pH} 2$ with $\mathrm{HCl}$ addition, there was no formation of $\mathrm{Au} \mathrm{NCs}$ (not shown). This is probably because the reduction ability of tyrosine in trypsin is activated with the alkaline pH. 22,27 Recently, Tan et al. have also investigated the amino-acid sequence in peptides for the synthesis of peptide-stabilized Au NPs. ${ }^{34}$ It was found that tyrosine and tryptophan showed fairly gold reduction ability of $\mathrm{AuCl}_{4}{ }^{-}$when present in the peptide sequence. In addition, $\mathrm{AuCl}_{4}{ }^{-}$ions have been reported to lead to the formation of Au hydroxy species such as $\left[\mathrm{AuCl}_{\mathrm{x}}(\mathrm{OH})_{4-\mathrm{x}}\right]^{-}(x=0-4)$ with alkaline $\mathrm{pH} \cdot{ }^{35}$ 

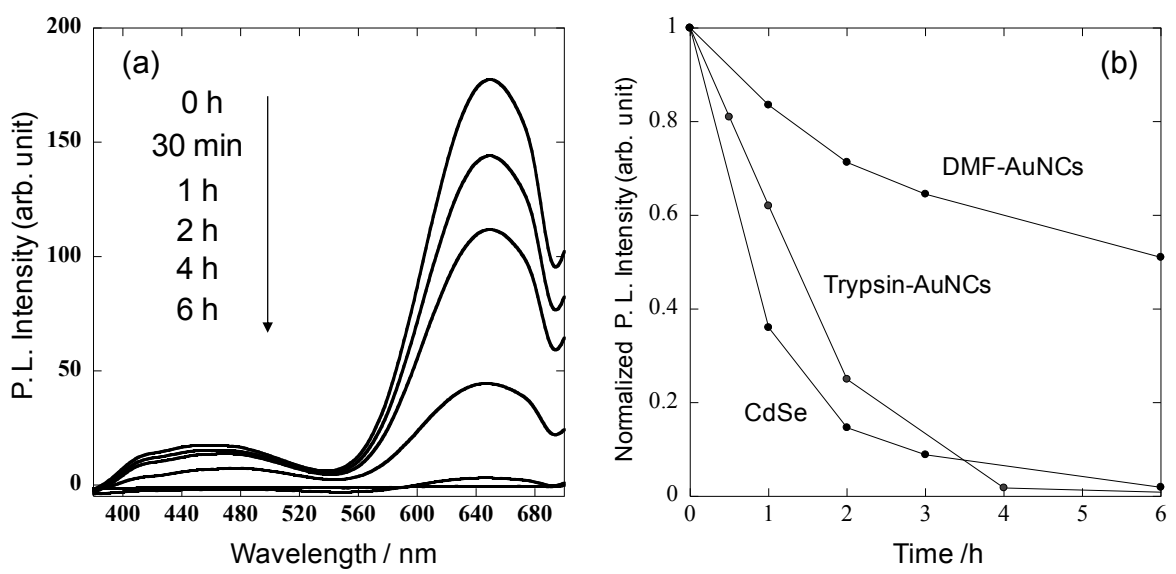

Fig. 4 (a) Photoluminescence spectra of trypsin-stabilized Au NCs at $\lambda_{\mathrm{ex}}=360 \mathrm{~nm}$ in water at $\mathrm{pH} 8$ as a function of the UV irradiation time $\left(356 \mathrm{~nm}, 2 \mathrm{~mW} / \mathrm{cm}^{2}\right)$ for up to $6 \mathrm{~h}$. (b) Normalized photoluminescence intensities of trypsin-stabilized Au NCs at $\lambda_{\mathrm{ex}}=360 \mathrm{~nm}$ as a function of the UV irradiation time $\left(356 \mathrm{~nm}, 1.3 \mathrm{~mW} / \mathrm{cm}^{2}\right)$ for up to $6 \mathrm{~h}$. For comparison, results on DMF-protected $\mathrm{Au} \mathrm{NCs}$ and CdSe in toluene, ${ }^{25}$ exposed to the same conditions, are also shown.

The formation of such hydroxylated species under the alkaline $\mathrm{pH}$ condition may lower the reduction potential of the Au ions, ${ }^{36}$ leading to an easier reduction of $\mathrm{Au}$ ions by tyrosine in trypsin. The involvement of tyrosine residues in the reduction of the $\mathrm{Au}$ ions was further confirmed by the observation of fluorescence from tyrosine before and after the reduction of $\mathrm{Au}$ ions by trypsin. The fluorescence of tyrosine is sensitive to oxidation, and the loss of fluorescence indicates the oxidation of tyrosine in protein. ${ }^{37}$ As shown in Fig. 3a, the fluorescence of tyrosine was observed in trypsin aqueous solution at $\mathrm{pH} \mathrm{12;} \mathrm{however,}$ most of the fluorescence of tyrosine residues in trypsin was lost in the trypsin-stabilized Au NCs, suggesting the involvement of tyrosine residues in the reduction of Au ions. It should be noted that some types of protein structures in trypsin should contribute to initiate the reduction of $\mathrm{AuCl}_{4}{ }^{-}$and the template scaffold in the formation of trypsin-stabilized Au NCs, since we could not obtain the fluorescent trypsin-stabilized Au NCs in the presence of the denaturant of $8 \mathrm{M}$ urea, which unfolded the protein (Fig. 3b).

\section{Photostability of trypsin-stabilized Au NCs}

Photochemical instability (i.e., decrease in fluorescence intensity against light irradiation) irreversibly destroys photoluminescence molecules stimulated by radiation within the excitation spectrum. This eliminates potentially useful photoluminescence properties. It has been reported that Au NCs are highly photostable when compared with organic fluorophores, such as fluorescein and rhodamin 6G, although the Au NCs were not as photostable as polymer-coated CdSe/ZnS quantum dots (QDs). ${ }^{38}$ Recently, we also reported that dimethylformamide (DMF)-protected $\mathrm{Au} \mathrm{NCs}$ that include at least $\mathrm{Au}_{8}$ and $\mathrm{Au}_{13}$ are much more photostable compared to CdSe QDs. ${ }^{25}$ In this study, the photostable properties of trypsin-stabilized Au NCs in water at $\mathrm{pH} 8$ were examined. Figure 4a shows photoluminescence spectra of trypsin-stabilized $\mathrm{Au} \mathrm{NCs}$ as a function of the UV light continuous irradiation time $\left(356 \mathrm{~nm}, 1.3 \mathrm{~mW} / \mathrm{cm}^{2}\right)$. For comparison, the results for DMF-protected $\mathrm{Au} \mathrm{NCs}$ and $\mathrm{CdSe}$ in toluene, ${ }^{25}$ exposed to the same light conditions, are also shown in the figure. The fluorescence intensities decreased to approximately $60 \%$ of their maximum after $1 \mathrm{~h}$ and disappeared after $4 \mathrm{~h}$ (Fig. 4b). The photostability of trypsin-stabilized Au NCs is high, similar to that of CdSe QDs. The high photostability of trypsin-stabilized $\mathrm{Au}$ NCs has an advantage concerning the analytical application of $\mathrm{Au}$ NCs for fluorescent sensing of metal ions. On the other hand, the photostability of trypsin-stabilized Au NCs is no better than those of DMF-protected Au NCs. The lower photostability of the trypsin-stabilized Au NCs compared to that of DMF-protected Au NCs may originate from the low stability of trypsin against UV light.

Analytical application of trypsin-stabilized $\mathrm{Au} \mathrm{NCs}$ for $\mathrm{Hg}^{2+}$ ion sensing

It has been reported that BSA- or lysozyme-stabilized fluorescent $\mathrm{Au}$ NCs can be used as sensitive and selective sensors of metal ions, such as $\mathrm{Hg}^{2+}$ ions, through fluorescence quenching by the $\mathrm{Hg}^{2+}-\mathrm{Au}^{+}$interaction. ${ }^{29-31}$ Here, the effect of metal ion addition on the fluorescence of trypsin-stabilized $\mathrm{Au} \mathrm{NCs}$ was investigated in the presence of $10 \mu \mathrm{M}$ of $\mathrm{Cu}^{2+}$, $\mathrm{Ni}^{2+}, \mathrm{Ca}^{2+}, \mathrm{Mg}^{2+}, \mathrm{Na}^{+}, \mathrm{Pb}^{2+}, \mathrm{Hg}^{2+}, \mathrm{Zn}^{2+}, \mathrm{Co}^{2+}$, or $\mathrm{Cd}^{2+}$ at $\mathrm{pH} 8$. Figure 5a shows the relative fluorescence $\left(I / I_{0}\right)$ in the presence of $10 \mu \mathrm{M}$ of the above metal ion. Only the addition of the $\mathrm{Hg}^{2+}$ ion resulted in the dominant quenching of the fluorescence of the $\mathrm{Au} \mathrm{NCs}$, although there was a slight quenching of fluorescence in the presence of other metal ions. Thus, the fluorescence quenching of trypsin-stabilized Au NCs can be used for $\mathrm{Hg}^{2+}$ ion sensing, similar to BSA- or lysozyme-stabilized fluorescent $\mathrm{Au}$ NCs. The fluorescence intensity decreased linearly over the $\mathrm{Hg}^{2+}$ concentration range of $50-600 \mathrm{nM}$ (Figs. 5b and 5c), but the quantitative decrease in the fluorescence intensity was not observed in the low concentration range of $0.5-10 \mathrm{nM}$. The limit of detection (LOD) for the $\mathrm{Hg}^{2+}$ ions was estimated to be $50 \pm 10 \mathrm{nM}$ from the minimum concentration in the linear region of fluorescence decreases. The LOD value for $\mathrm{Hg}^{2+}$ ion is higher than those of BSA-stabilized Au NCs $(0.5 \mathrm{nM})$ and lysozyme-stabilized Au NCs $(10 \mathrm{nM}) .{ }^{29}$ The advantage of trypsin-stabilized Au NCs is the wide and low quantitative detection range of $50-600 \mathrm{nM}$, compared to those of BSA-stabilized Au NCs (the fluorescence decreases in the linear region of $1-20 \mathrm{nM})^{29}$ and Lyz-stabilized $\mathrm{Au} \mathrm{NCs}$ (the fluorescence decreases in the linear region of $100-2000 \mathrm{nM}) .^{30}$ If it is assumed that the LOD value for the $\mathrm{Hg}^{2+}$ ion sensing is defined as the minimum concentration in the linier region of fluorescence decreases, the LOD values of 

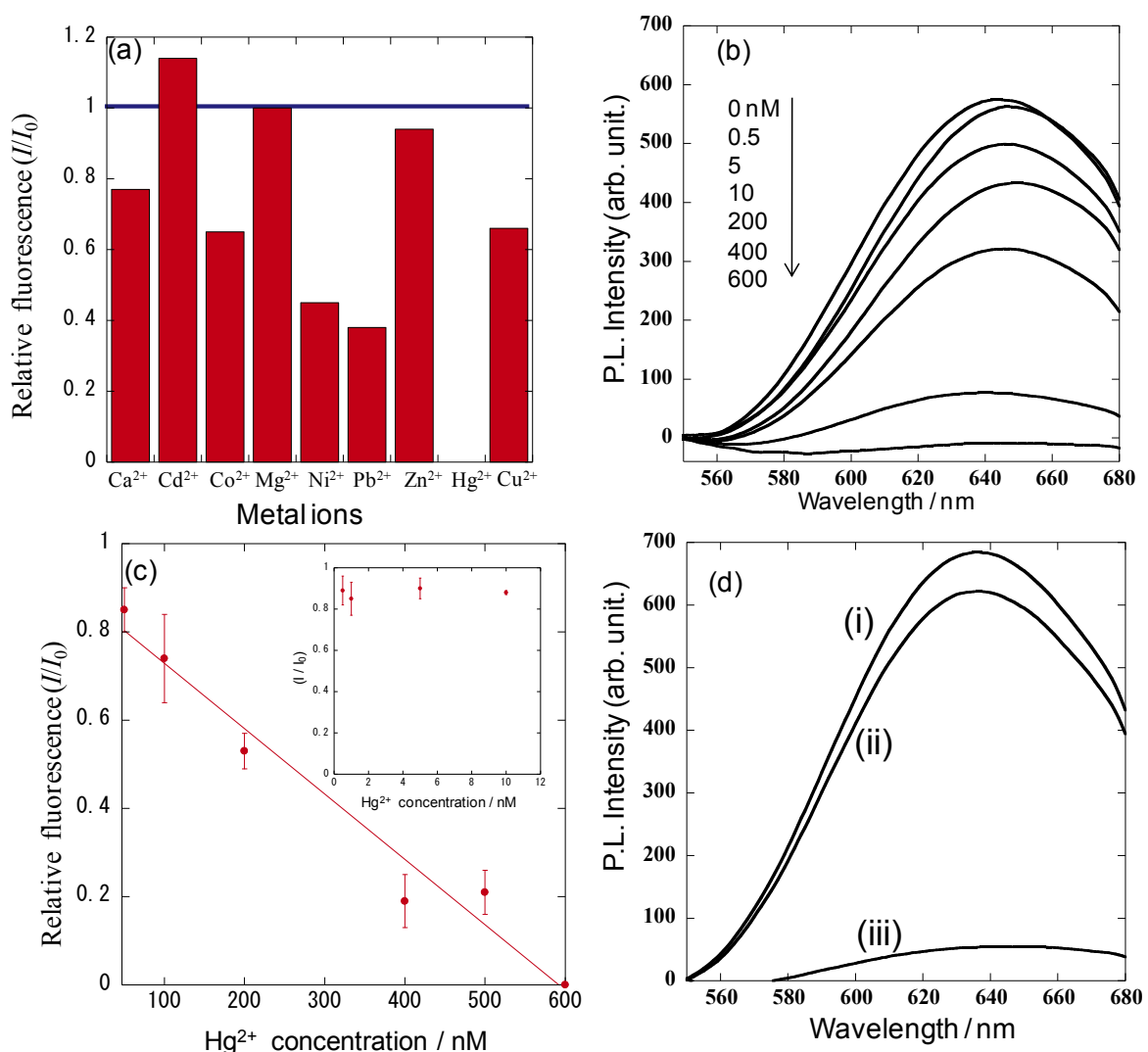

Fig. 5 (a) Relative fluorescence $\left(I / I_{0}\right)$ of trypsin-stabilized Au NCs at $\lambda_{\text {ex }}=360 \mathrm{~nm}$ in the presence of $10 \mu \mathrm{M}$ of $\mathrm{Cu}^{2+}, \mathrm{Ni}^{2+}, \mathrm{Ca}^{2+}, \mathrm{Mg}^{2+}, \mathrm{Na}^{+}, \mathrm{Pb}^{2+}, \mathrm{Hg}^{2+}, \mathrm{Zn}^{2+}, \mathrm{Co}^{2+}$, or $\mathrm{Cd}^{2+}$ at $\mathrm{pH} 8$. I $I_{0}$ and $\mathrm{I}$ : the photoluminescence intensities of trypsin-stabilized Au NCs in the absence and presence of the above ions. (b) Photoluminescence intensities of trypsin-stabilized Au NCs at $\lambda_{\mathrm{ex}}=360 \mathrm{~nm}$ with increasing concentration of $\mathrm{Hg}^{2+}$ ions at $\mathrm{pH} 8$ (concentrations shown in the figure). (c) $I / I_{0}$ of trypsin-stabilized $\mathrm{Au} \mathrm{NCs}$ at $\lambda_{\mathrm{ex}}=360 \mathrm{~nm}$ as a function of $\mathrm{Hg}^{2+}$ ion (inset shows the concentration range $0.5-10 \mathrm{nM}$ ). (d) Photoluminescence intensities of trypsin-stabilized Au NCs at $\lambda_{\mathrm{ex}}=360 \mathrm{~nm}$ (i) in water at $\mathrm{pH} 8$; (ii) in coexistence with the following metal ions at $\mathrm{pH} 8: \mathrm{Cu}^{2+}, \mathrm{Ni}^{2+}, \mathrm{Ca}^{2+}, \mathrm{Mg}^{2+}, \mathrm{Na}^{+}, \mathrm{Pb}^{2+}, \mathrm{Zn}^{2+}, \mathrm{Co}^{2+}$, and $\mathrm{Cd}^{2+}$ (each metal ion concentration, $500 \mathrm{nM}$ ); (iii) in coexistence with the following metal ions at $\mathrm{pH} 8$ : $\mathrm{Cu}^{2+}, \mathrm{Ni}^{2+}, \mathrm{Ca}^{2+}, \mathrm{Mg}^{2+}, \mathrm{Na}^{+}, \mathrm{Pb}^{2+}, \mathrm{Zn}^{2+}, \mathrm{Co}^{2+}, \mathrm{Cd}^{2+}$, and $\mathrm{Hg}^{2+}$ (each metal ion concentration, $500 \mathrm{nM}$ ).

protein-stabilized $\mathrm{Au} \mathrm{NCs}$ are as follows: $1 \mathrm{nM}$ for BSA-stabilized Au NCs, $50 \mathrm{nM}$ for trypsin-stabilized Au NCs, and $100 \mathrm{nM}$ for lysozyme-stabilized Au NCs. To further demonstrate the potential practical application of detecting $\mathrm{Hg}^{2+}$ ions in real samples using trypsin-stabilized Au NCs, $600 \mathrm{nM}$ of $\mathrm{Hg}^{2+}$ was spiked in non filtered aqueous solutions from tap, mineral, and river water (the Yodo River in Osaka, Japan). The fluorescence of trypsin-stabilized Au NCs completely disappeared in the presence of $\mathrm{Hg}^{2+}$ ions $(600 \mathrm{nM})$, corresponding to the values of $I / I_{0} \sim 0$ for tap water, mineral water, and river water. The naked-eye detection of $\mathrm{Hg}^{2+}$ ions is possible for the $\mathrm{Hg}^{2+}$ concentrations of more than $600 \mathrm{nM}$.

We also examined the possibility of quantitatively detecting $\mathrm{Hg}^{2+}$ ions $(500 \mathrm{nM})$ in aqueous solution using trypsin-stabilized $\mathrm{Au} \mathrm{NCs}$, in coexistence with interference metal ions: $\mathrm{Cu}^{2+}$, $\mathrm{Ni}^{2+}, \mathrm{Ca}^{2+}, \mathrm{Mg}^{2+}, \mathrm{Na}^{+}, \mathrm{Pb}^{2+}, \mathrm{Zn}^{2+}, \mathrm{Co}^{2+}$, and $\mathrm{Cd}^{2+}$ (each metal ion concentration was $500 \mathrm{nM}$ ). The addition of the above-mentioned metal ions into aqueous solutions of trypsin-stabilized Au NCs $(5 \mu \mathrm{M})$ resulted in a slight decrease in the fluorescence intensity (Fig. 5d (ii)). The further addition of the $\mathrm{Hg}^{2+}$ ion of $500 \mathrm{nM}$ into this solution led to a dramatic decrease in the fluorescence intensity $\left(I / I_{0}=0.08\right)$ (Fig. $5 \mathrm{~d}$ (iii)). From the fluorescence intensity in the presence of $\mathrm{Hg}^{2+}$, we estimated the concentration of $\mathrm{Hg}^{2+}$ ions to be $540 \mathrm{nM}$, using the calibration curve of Fig. 5c. This is almost consistent with the concentration $(500 \mathrm{nM})$ of previously spiked $\mathrm{Hg}^{2+}$. These features contribute to the selectivity in the quantitative detection of $\mathrm{Hg}^{2+}$ ions, even in the presence of interference ions.

The above results indicate that the fluorescence of trypsin-stabilized Au NCs was particularly quenched by $\mathrm{Hg}^{2+}$, and therefore the Au NCs can be used as sensors for sensitive and selective $\mathrm{Hg}^{2+}$ detection. The specific characteristics of Au NCs reflect the specific interaction between trypsin-stabilized $\mathrm{Au} \mathrm{NCs}$ and $\mathrm{Hg}^{2+}$. Trypsin has rich amino acids with thiol-groups (6 cysteine and 3 methionine). $\mathrm{Hg}^{2+}$ ions can strongly bind to the thiol-compounds due to the fact that the thiol-group has a stronger binding of $\mathrm{Hg}^{2+}$ to thiol-sites than do other metal ions. ${ }^{39}$ The stability constants between heavy metal ions and the chelating ligand, like L-cysteine, are $\log K(\mathrm{Hg})=10.1, \log K(\mathrm{~Pb})=4.1, \log K(\mathrm{Cd})=3.2$, respectively. ${ }^{40}$ It is also known that in aqueous solutions, $\mathrm{Hg}^{2+}$ spontaneously reacts with $\mathrm{Au}$ to form a $\mathrm{Au}$ amalgam..$^{36,39,41}$ One possible explanation for the specific interaction between trypsin-stabilized $\mathrm{Au} \mathrm{NCs}$ and $\mathrm{Hg}^{2+}$ is as follows: the $\mathrm{Hg}^{2+}$ ions deposit on the surface of the trypsin-stabilized Au NCs because of the strong binding of $\mathrm{Hg}^{2+}$ to thiol-sites, which results in the accumulation 
of trypsin on the Au surfaces. Moreover, by direct interaction with the Au surfaces, $\mathrm{Hg}^{2+}$ spontaneously reacts with $\mathrm{Au}$ to form a $\mathrm{Au}$ amalgam, resulting in fluorescence quenching of the trypsin-stabilized Au NCs. Based on these results, we consider that trypsin-stabilized $\mathrm{Au}$ NCs can selectively detect $\mathrm{Hg}^{2+}$ with a relatively high limit of detection via the specific interaction between trypsin-stabilized $\mathrm{Au} \mathrm{NCs}$ and $\mathrm{Hg}^{2+}$.

\section{Conclusion}

Trypsin-stabilized fluorescent Au NCs with a red emission of $640 \mathrm{~nm}$ in basic aqueous solution were synthesized using trypsin as a reducing and stabilizing agent. The trypsin-stabilized $\mathrm{Au}$ NCs are approximately $1 \mathrm{~nm}$ in size. The CD spectroscopy of trypsin-stabilized Au NCs showed a large conformational change by the encapsulation of Au NCs in trypsin, which contrasted with the case of BSA-Au NCs, which had little effect on the structure of the BSA scaffolds. The photostability of trypsin-stabilized Au NCs was similar to that of CdSe QDs, while it was no better than that of DMF-protected Au NCs. The fluorescence was particularly quenched by $\mathrm{Hg}^{2+}$, and therefore the Au NCs can be used as sensors for sensitive and selective $\mathrm{Hg}^{2+}$ detection to a detection limit of $50 \pm 10 \mathrm{nM}$ and the quantitative detection of $\mathrm{Hg}^{2+}$ in the wide and low concentration range of $50-600 \mathrm{nM}$.

\section{Acknowledgements}

We thank Dr. Y. Hagihara and Dr. Y. Shigeri at the National Institute of Advanced Industrial Science and Technology (AIST) for measurements of the CD spectra, Dr. Takahasi and Dr. Yamazaki at Kobelco Research Inst. for measurements of the XPS spectra and TEM images. This study was partially supported by a Grant-in-Aid for Scientific Research (B) (Nos. 23360361 (to H. K.) and 22350040 (to R. Y.)) from the Japan Society for the Promotion of Science (JSPS). This study was supported by the "Strategic Project to Support the Formation of Research Bases at Private Universities": Matching Fund Subsidy from MEXT.

\section{References}

1. D. Michael and P. Mingos, Gold Bull., 1984, 17, 5.

2. S. Chen, R. S. Ingram, M. J. Hostetler, J. J. Pietron, R. W. Murray, T. G. Schaaff, J. T. Khoury, M. M. Alvarez, and R. L. Whetten, Science, 1998, 280, 2098.

3. T. G. Schaaff, M. N. Shafigullin, J. T. Khoury, I. Vezmar, R. L. Whetten, W. G. Cullen, P. N. First, C. Gutierrez-Wing, J. Ascensio, and M. J. Jose-Yacaman, J. Phys. Chem. B, 1997, 101,7885 .

4. L. A. Peyser, A. E. Vinson, A. P. Bartko, and R. M. Dickson, Science, 2001, 291, 103.

5. M. Haruta, Chem. Rec., 2003, 3, 75.

6. S. Link, A. Beeby, S. FitzGerald, M. A. El-Sayed, T. G. Schaaff, and R. L. Whetten, J. Phys. Chem. B, 2002, 106, 3410 .

7. J. Zheng, P. R. Nicovich, and R. M. Dickson, Annu. Rev. Phys. Chem., 2007, 58, 409.

8. R. Jin, Nanoscale, 2010, 2, 343.

9. C. M. Aikens, J. Phys. Chem. Lett., 2011, 2, 99.

10. J. Zheng, C. Zhang, and R. M. Dickson, Phys. Rev. Lett.,
2004, 93, 077402.

11. Y. Negishi, Y. Takasugi, S. Sato, H. Yao, K. Kimura, and T. Tsukuda, J. Am. Chem. Soc., 2004, 126, 6518.

12. R. Balasubramanian, R. Guo, A. J. Mills, and R. W. Murray, J. Am. Chem. Soc., 2005, 127, 8126.

13. Y. Negishi, K. Nobusada, and T. Tsukuda, J. Am. Chem. Soc., 2005, 127, 5261.

14. I. Hussain, S. Graham, Z. Wang, B. Tan, D. C. Sherrington, S. P. Rannard, A. I. Cooper, and M. Brust, J. Am. Chem. Soc., 2005, 127, 16398.

15. H. Duan and S. Nie, J. Am. Chem. Soc., 2007, 129, 2412.

16. Y. Bao, C. Zhong, D. M. Vu, J. P. Temirov, R. B. Dyer, and J. S. Martinz, J. Phys. Chem. C, 2007, 111, 12194.

17. A. P. Gies, D. M. Hercules, A. E. Gerdon, and D. E. Cliffel, J. Am. Chem. Soc., 2007, 129, 1095.

18. M. W. Heaven, A. Dass, P. S. White, K. M. Holt, and R. W. Murray, J. Am. Chem. Soc., 2008, 130, 3754.

19. M. Zhu, C. M. Aikens, F. J. Hollander, G. C. Schatz, and R. Jin, J. Am. Chem. Soc., 2008, 130, 5883.

20. X. Liu, C. Li, J. Xu, J. Lv, M. Zhu, Y. Guo, S. Cui, H. Liu, S.Wang, and Y. Li, J. Phys. Chem. C, 2008, 112, 10778.

21. C. M. Aikens, J. Phys. Chem. C, 2008, 112, 19797.

22. J. Xie, Y. Zheng, and J. T. Ying, J. Am. Chem. Soc., 2009, $131,888$.

23. Z. Wu and R. Jin, ACS Nano, 2009, 3, 2036.

24. G. Shafai, S. Hong, M. Bertino, and T. Rahman, J. Phys. Chem. C, 2009, 113, 12072.

25. H. Kawasaki, H. Yamamoto, H. Fujimori, R. Arakawa, Y. Iwasaki, and M. Inada, Langmuir, 2010, 26, 5926.

26. M. B. Dickerson, K. H. Sandhage, and R. R. Naik, Chem. Rev., 2008, 108, 4935.

27. (a) S. Si, R. R. Bhattacharjee, A. Banerjee, and T. K. Mandal, Chem.-Eur. J., 2006, 12, 1256; (b) S. Si and T. K. Mandal, Chem.-Eur. J., 2007, 13, 3160.

28. R. R. Bhattacharjee, A. K. Das, D. Haldar, S. Si, A. Banerjee, and T. K. Mandal, J. Nanosci. Nanotechnol., 2005, 5, 1141.

29. J. Xie, Y. Zheng, and J. Y. Ying, Chem. Commun., 2010, 46, 961.

30. H. Wei, Z. Wang, L. Yang, S. Tian, C. Houc, and Y. Lu, Analyst, 2010, 135, 1406.

31. Y.-H. Lin and W.-L. Tseng, Anal. Chem., 2010, 82, 9194.

32. A. Tanaka, Y. Takeda, M. Imamura, and S. Sato, Phys. Rev. $B, \mathbf{2 0 0 3}, 68,195415$.

33. G. A. Simms, J. D. Padmos, and P. Zhanga, J. Chem. Phys., 2009, 131, 214703.

34. Y. N. Tan, J. Y. Lee, and D. I. C. Wang, J. Am. Chem. Soc., 2010, 132, 5677.

35. P. J. Murphy and M. S. LaGrange, Geochim. Cosmochim. Acta, 1998, 62, 3515.

36. K. Hamaguchi, H. Kawasaki, and R. Arakawa, Colloids Surf., A, 2010, 367, 167.

37. J. Xie, J. Y. Lee, D. I. C. Wang, and Y. P. Ting, ACS Nano, 2007, 5, 429.

38. C.-A. J. Lin, T.-Y. Yang, C.-H. Lee, S. H. Huang, R. A. Sperling, M. Zanella, J. K. Li, J.-L. Shen, H.-H. Wang, H.-I. Yeh, W. J. Parak, and W. H. Chang, ACS Nano, 2009, $3,395$.

39. X. Xiaohe, T. G. Thundat, G. M. Brown, and H.-F. Ji, Anal. Chem., 2002, 74, 3611.

40. (a) C. J. Yu and W. L. Tseng, Langmuir, 2008, 24, 12717. (b) G. K. Darbha, A. K. Singh, U. S. Rai, E. Yu, H. T. Yu, and P. C. Ray, J. Am. Chem. Soc., 2008, 130, 8038.

41. K. P. L. Anshup and T. Pradeep, Gold Bull., 2009, 42, 144. 